\title{
The evolutionary functions of imagination and fiction and how they may contribute to psychological wellbeing during a pandemic
}

\author{
**Please click $\underline{\text { HERE }}$ for the latest version of this preprint**
}

\author{
Valerie van Mulukom ${ }^{1^{*}}$, Mathias Clasen ${ }^{2}$ \\ ${ }^{1}$ Brain, Belief, and Behaviour Lab, Centre for Trust, Peace and Social Relations, Coventry, United \\ Kingdom \\ ${ }^{2}$ Recreational Fear Lab, School of Communication of Culture, Department of English, Aarhus University, \\ Aarhus, Denmark \\ * Correspondence: \\ Corresponding Author \\ ac2492@ coventry.ac.uk
}

Short title: Imaginative and narrative simulation

PLEASE NOTE THAT THIS IS A PRE-PRINT. WHILE THIS VERSION OF THE DOCUMENT IS THE MOST COMPLETE AND MOST RECENT, IT SHOULD BE REGARDED AS A WORK IN PROGRESS.

WE URGE ANY PARTIES INTERESTED IN THIS WORK TO CONTACT THE LEAD AUTHOR (LISTED ABOVE) FOR FURTHER DETAILS OR UPDATES. WE REQUEST THAT THESE FINDINGS ARE REPORTED AS TENTATIVE, AND THEIR STATUS AS A PREPRINT. 


\begin{abstract}
The COVID-19 pandemic caused widespread social disruption and lockdowns, with negative consequences for psychological wellbeing worldwide. We argue that imaginative and narrative simulation - the mental simulation of events, sourced from memory and fiction, brought together through narrative may have substantial positive contributions to psychological wellbeing during the pandemic. In particular, we propose that this simulation is a tool to support (i) planning and future thought, (ii) coping and emotion regulation, (iii) bonding and social needs, and (iv) identity and worldviews. We suggest that these functions can contribute to coping during the pandemic, though we also address the maladaptive effects of the functions on psychological wellbeing, such as rumination. We put forward our framework, include relevant research on the evolutionary functions of simulation through imagination and fiction, and review relevant studies of the effects of imagination and fiction on psychological wellbeing during the COVID-19 pandemic. In light of previous research and the negative psychological effects of COVID-19 disruptions and lockdowns, we suggest that there is much scope for future research on this topic.
\end{abstract}

Keywords: imagination, fiction, evolution, simulation, psychological wellbeing 


\section{Imagination and fiction through memory, mental simulation, and narrative processing}

In the early months of 2020, the rapid spread of COVID-19 around the world led to the declaration of a pandemic. With this came government-mandated restrictions, such as lockdowns and isolation at home. These restrictions, while in the interest of public health, have a number of knock-on effects, such as worsened mental health (Pierce et al., 2020; van Mulukom et al., 2021), increased loneliness (Groarke et al., 2020) and even increased hostility towards certain groups (Tessler et al., 2020). In this paper, we put forward an overview of evolutionary functions of simulation through imagination and fiction (supported by memory and narrative processing), their effects on psychological health, and how this may be applied in the context of pandemics. We suggest that despite the potential, there has been little research on the link between imagination and fiction and psychological wellbeing, and little practical application of imagination and fiction to address the COVID-19 pandemic's impact on psychological wellbeing. We conclude with suggestions for future directions.

We will conceptualize imagination and fiction as the mental simulation of events (Barsalou, 2009; Shanton \& Goldman, 2010), sourced from memory, brought together through narrative. With mental simulation we will mean the generation of persons, locations, and objects, not derived from immediate perceptual input, in the mind's eye (van Mulukom, 2019), with imagination the powerful cognitive capacity used to simulate events, supported by core brain regions of the default mode network (Schacter et al., 2007), and with fiction stories about made-up people and events. A distinction can be made between intentional and unintentional imagination (or event simulation and mind-wandering), which recruit partially overlapping brain regions in the default mode network, though not to the same extent (Stawarczyk \& D'Argembeau, 2015). Here we will focus on intentional imagination unless specified otherwise. Fiction is both the outcome and the instigator of imagination: When we consume fictional stories (constructed by others), we simulate entire fictional worlds populated by fictional people within our minds. Imaginative activity consists of both endogenously generated simulations, as in future planning, and exogenously prompted simulations, e.g. by a movie or a novel.

The building blocks of event simulation come from memory: because memory is fundamentally constructive rather than reproductive (Bartlett, 1932), this means that memory details can be flexibly recombined into novel sets (Schacter \& Addis, 2007), such as imagined events, whether future (van Mulukom, 2013), counterfactual (De Brigard et al., 2013) or other hypothetical events (Szpunar et al., 2007). Events from an individual's remembered past, experienced present and anticipated future are brought together into a unified whole through narrative processing (McAdams, 2001). Narrative processing organizes thought through story devices (e.g., plot, intention, character, outcome and theme) as opposed to through abstract categories or concepts as in analytical processing (Bruner, 1986). 
Within event simulation, we can focus on certain circumstances, such as problems that need solving or issues that need overcoming, but we can also focus on persons, e.g. what it is like to be other people (Perner \& Kühberger, 2005). We suggest that both aspects (simulations focused on circumstances or on persons) are hugely important for humans to deal with the world around them (van Mulukom \& Geertz, 2021), which is inherently physical as well as social. In similar vein, it has been proposed that simulations provide information and (at times deeply felt) experiences (Mar \& Oatley, 2008). These aspects can be summarized by the notion that the overarching process we describe - imaginative and narrative simulation - draws upon the central human ability and natural individual tendency for social learning: learning knowledge (whether 'factual information' or experiences, perspectives, etc.) and skills from other humans. This conceptualization incorporates the notion that imaginative and narrative simulation is used to make sense of novel or non-typical situations, and the cumulative, collaborative creation of skills and knowledge resulting from it (see also Bietti et al., 2019). These features collaborative efforts to obtain and share novel information - make imaginative and narrative simulation particularly adaptive in situations of fast and unforeseen changes, such as disease outbreaks and other natural catastrophes (Bietti et al., 2019).

\section{A framework of imaginative and narrative simulation}

\subsection{Evolutionary functions of imaginative and narrative simulation, and their psychological effects}

Fiction and engaging in imagination (e.g., pretend play, hypothetical thinking) are human universals (Brown, 1991), which occur all over the world, have been around for a very long time (Da Silva \& Tehrani, 2016), and come naturally to people, from a young age onwards (Taylor, 2013); together these features suggest that imaginative and narrative simulation may be an important human adaptation (Smith et al., 2017). While we will refrain here from a more in-depth historical overview of the evolution of imagination per se (e.g., Fuentes, 2020), we will instead review the evolutionary psychology and cognitive science literature for evolutionary functions of imagination and fiction, in particular as arising from their simulative capacities. Simulation through memory, imagination or fiction has been theorized to serve several functions, with researchers typically focusing primarily on one function at the time, including future-oriented (Bulley et al., 2020), predictive (Clark, 2015), communicative (Mahr \& Csibra, 2018), and social functions (Mar \& Oatley, 2008). Our framework will incorporate and build on this previous work rather than deviating from it, and integrate them into one overarching theory focusing on simulation as a result of imagination and fiction.

Here, we propose there are four main categories of evolutionary functions of simulation through imagination and fiction: (1) planning and future thought, or simulating to prepare for the future; (2) 
coping and emotion regulation, or simulating to regulate emotions and solve emotional problems; (3) bonding and social needs, or simulating to develop, maintain or nurture relationships; (4) identity and worldviews, or simulating to support one's self-concept and identity. Previous singularly-focused theories of imagination can similarly roughly be categories under these functions: theories focused on future-oriented (Bulley et al., 2020) and predictive (Clark, 2015) functions broadly fall under the planning and future thought function, whereas the previously proposed communicative (Mahr \& Csibra, 2018) and social function theories (Mar \& Oatley, 2008) fall under the bonding and other social needs function. We note that whilst discussing evolutionary functions of simulation, this does not mean that they are automatically adaptive (e.g., conferring a fitness benefit to individuals when it emerged), nor does it mean that, if they are indeed adaptive, that their adaptive benefits lie in their effects on psychological wellbeing. For example, our proposed functions can also be maladaptive, such as in the case of overthinking, conspiracy thinking, social neglect, and excessive self-focus, to mention a few.

Other non-singular functions or evolutionary theories of the main mechanisms of interest imagination, fiction, memory and narrative processing - have also been put forward however (Bluck et al., 2005; Gottschall, 2012; Tay et al., 2018), though each focusing on slightly different perspectives including practical functions of autobiographical memory (Bluck et al., 2005), functions of enjoyment in media transportation (Green et al., 2004), positive effects on psychological health through the arts and humanities (Tay et al., 2018). Importantly, our framework for imaginative and narrative simulation combines the relevant mechanisms, and shows overlap with the different perspectives of previous theories; see Table 1. One aspect that is central to these theories, but not incorporated as a function in our framework is immersion (Tay et al., 2018) or transportation (Green et al., 2004). We suggest that this is likely a moderator of how well fiction can engage attention and have an effect on psychological wellbeing, but that this is not a direct function of simulation.

We will now discuss the proposed functions of imaginative and narrative simulation and their effects on psychological wellbeing, followed by a comparison of our proposed framework to previous theories, before examining our framework within the context of the COVID-19 pandemic. 
Table 1

Theoretical frameworks for functions and psychological effects of imagination, memory, and fictional narrative and arts

\begin{tabular}{|c|c|c|c|c|}
\hline Focus \& source & $\begin{array}{l}\text { Planning and other } \\
\text { future thought }\end{array}$ & $\begin{array}{l}\text { Coping and } \\
\text { emotion regulation }\end{array}$ & $\begin{array}{l}\text { Bonding and other } \\
\text { social needs }\end{array}$ & $\begin{array}{l}\text { Identity and } \\
\text { worldviews }\end{array}$ \\
\hline $\begin{array}{l}\text { Functions of } \\
\text { autobiographical } \\
\text { memory } \\
\text { Bluck et al. (2005) }\end{array}$ & $\begin{array}{l}\text { Directive function: } \\
\text { Directing present } \\
\text { and future behavior }\end{array}$ & $\begin{array}{l}\text { Directive function: } \\
\text { Directing present } \\
\text { and future behavior }\end{array}$ & $\begin{array}{l}\text { Social function: } \\
\text { Creating, } \\
\text { maintaining, and } \\
\text { representing social } \\
\text { connections }\end{array}$ & $\begin{array}{l}\text { Self function: Self- } \\
\text { definition and } \\
\text { continuity }\end{array}$ \\
\hline $\begin{array}{l}\text { Enjoyment } \\
\text { through media } \\
\text { transportation } \\
\text { Green et al. (2004) }\end{array}$ & $\begin{array}{l}\text { Enjoyment through } \\
\text { transformation }\end{array}$ & $\begin{array}{l}\text { Enjoyment through } \\
\text { escaping the self; } \\
\text { Mood management }\end{array}$ & $\begin{array}{l}\text { Enjoyment through } \\
\text { connections with } \\
\text { characters }\end{array}$ & $\begin{array}{l}\text { Enjoyment through } \\
\text { transformation }\end{array}$ \\
\hline $\begin{array}{l}\text { Human flourishing } \\
\text { through arts and } \\
\text { humanities } \\
\text { Tay et al. (2018) }\end{array}$ & - & $\begin{array}{l}\text { Embeddedness: } \\
\text { socio-cognitive } \\
\text { psychological } \\
\text { processes underlying } \\
\text { the development of } \\
\text { particular } \\
\text { perspectives, habits, } \\
\text { or skills }\end{array}$ & $\begin{array}{l}\text { Socialization: degree } \\
\text { to which individuals } \\
\text { take on various roles } \\
\text { and identities within } \\
\text { communities and } \\
\text { cultures }\end{array}$ & $\begin{array}{l}\text { Reflectiveness: } \\
\text { intentional, } \\
\text { cognitive-emotional } \\
\text { process for } \\
\text { developing, } \\
\text { reinforcing, or } \\
\text { discarding one's } \\
\text { habits, character, } \\
\text { values, or worldview }\end{array}$ \\
\hline
\end{tabular}

\subsection{Planning and future thought}

The human capacity for 'mental time travel' (Tulving, 1985), defined as the ability to project ourselves imaginatively into future, past, or alternative scenarios, is arguably one of the greatest advantages of the imagination. This capacity allows us to try out potential scenarios without having to endure the full costs of the experience, meaning that both successful and unsuccessful plans of action can be simulated at no lived cost (Suddendorf \& Corballis, 2007), such as in the domains of hunting or mating. Process simulations may be more beneficial than outcome simulations: In a study where college freshmen simulated either the process (studying well) or the outcome (high grade) of a good exam, it was found that process simulation improved studying and subsequent grades through enhanced planning and reduced anxiety (Pham \& Taylor, 1999). Interestingly, fiction is crucially focused on providing process simulation: We follow characters as they try to solve some problem (e.g., courting someone, or fighting zombies) with much less detail on the actual outcome (e.g., marriage, or survival or death); narratives are about "the road", rather than "the inn to which it leads" (Bruner, 2002, p. 20). In this sense, fiction and storytelling is perceived as information acquisition (Scalise Sugiyama, 2001) for use in future events.

On the other hand, an overactivation of core regions in the default mode network has been associated with higher levels of rumination and lower levels of reflection in individuals with major 
depressive disorder (Hamilton et al., 2011). This may be due to individuals focusing too much on their present mental states and specific past experiences, rather than the future (Zhou et al., 2020) or the perspective of others. It has been suggested that fiction focuses on threat and negative circumstances (or ill fortune in short) exactly because it is a safe way to engage in anticipatory problem-solving (REF). Interestingly, some research has similarly found that when imagination roams free, it frequently turns to unpleasant topics. One study sampled the content of participants' mind-wandering and found a preponderance of positive topics $(42.5 \%)$, but also a substantial amount of unpleasant ones (26.5\%) (Killingsworth \& Gilbert, 2010). Thinking about unpleasant or even neutral topics was furthermore associated with lower levels of happiness than when one is engaged in everyday activities. This mood change appears to be the effect, rather than the cause, of the mind-wandering (though see Poerio et al., 2013). However, it should be noted that this is unintentional imagination (e.g., mind-wandering), which has been strongly and positively associated with symptoms of depression, anxiety, and stress, while intentional imagination (e.g., focused simulation) is only weakly and negatively related to these symptoms (Seli et al., 2019).

This function of imaginative and narrative simulation shows significant overlap with a number of previous theories about evolutionary and adaptive functions, such as the directive function of autobiographical memory, in which memory of events is used to predict future events, thus guiding future behavior and thought, facilitating goal-setting and decision-making, and contributing to problem--solving (Bluck et al., 2005); transportation in media as a form of transformation, which proposes that transportation in media helps individuals expand their horizons through new information, resources and insights that may be outside of the individuals' normal experience (Green et al., 2004); and in evolutionary theories that fiction functions a low cost source of information, a way to vicariously engage with other people's experiences and learning from them, and as cognitive play, a safe way of engaging with problems and threats (Gottschall, 2012). Storytelling thus transmits survival-relevant information through narratives, which may constitute both a larger body of knowledge and less risky and laborious to acquire than first-hand experience (Bietti et al., 2019). Common to each of these theories is the idea that new information about actions and processes can be gained through imaginative and narrative simulation in a safe way which may inform future decisions and actions.

\subsection{Coping and emotion regulation}

There is a long tradition of research investigating how imagination supports anticipatory and proactive coping (Aspinwall \& Taylor, 1997). Being able to generate detailed simulations allows individuals to more successfully regulate their emotions and solve problems (see for an overview, Taylor et al., 1998), for example through the tolerating, mastering, or even reducing of threat expression, i.e. managing 
phobias without having to go through actual exposure (Reddan et al., 2018). The effect of fiction on emotion is well-known (Mar et al., 2011): Fiction, such as novels and films, can induce strong emotional states (Oatley et al., 2006). This experience of emotion in turn can help build emotion regulation, in particular for individuals who typically are avoidant of, or resistant to, their emotions (Dal Cin et al., 2004; Djikic et al., 2009). However there may also be a negative side to imagining dangerous situations: repeatedly poring over worst-case scenarios that likely will never happen has been associated with anxiety (Grupe \& Nitschke, 2013). This can paralyze people rather than motivate them to action. Similarly, excessive self focus has been associated with negative outcomes for psychological wellbeing (e.g., depressive symptoms), as it can lead to self-derogation, a detrimental focus on one's shortcomings (Pyszczynski \& Greenberg, 1987), or discrepancies from an ideal self (Higgins, 1989); see for an overview, Luyten and Fonagy (2016). Thus, excessive imagining may interfere with proper functioning in everyday life and human interaction, though such behavior is generally associated with other, underlying psychological issues such as dissociation and obsessive-compulsive thoughts and behavior (Somer et al., 2016).

The coping and emotional regulation function of imaginative and narrative simulation is mirrored in previous theories of evolutionary functions including the directive function of autobiographical memory, in which memories of emotional, personally significant experiences are used to better understand the inner world of oneself and others, thus informing and guiding present and future thought and behavior (Bluck et al., 2005); and transportation into media as a way to escape or reduce the stress of personal concerns and problems, and to manage one's mood by increasing positive, or decreasing negative affect (Green et al., 2004). The embeddedness of imaginative and narrative simulation allows for the development of perspectives and skills, like self-efficacy, self-regulation, and emotion regulation (Tay et al., 2018).

\subsection{Bonding and social needs}

Imagining events told by storytellers around the campfire in hunter-gatherer societies may not only confer information about how to hunt game and other relevant experiences, but also coordinate group behavior and facilitate cooperation by providing tribe members with social information about norms, rules, and expectations (incl. regarding social interactions and taboos) in a given group (Biesele, 1986; Smith et al., 2017; Smith, 2010; Wiessner, 2014). While oral storytelling traditions may not be as common in modern societies, it has been suggested that storytelling which conveys social and cooperative norms has played a crucial role in the evolution of human cooperation by coordinating group behavior (Coe et al., 2006; Smith et al., 2017). 
Outside of storytelling of norms, simply simulating social interaction with members of an outgroup (Crisp \& Turner, 2009) leads to positive changes in intergroup perception and behavior, through reduced outgroup threat, reduced anxiety, and increased trust (Miles \& Crisp, 2014; Vezzali et al., 2012). Imagining being with one's significant other also increases bonding with them and reduces feelings of loneliness (Poerio et al., 2015, 2016). Similarly, parasocial relationships, or relationships imagined through fiction (incl. treating a fictional character as a human being; Giles, 2012), can have very similar effects to 'real life' relationships: they can give a sense of belonging (Derrick et al., 2009), reducing loneliness, and increase self-esteem (Derrick et al., 2008; though see Eyal \& Te'eni-Harari, 2013). Identification with the main character in Harry Potter novels correlated with reduced prejudice toward stigmatized groups (Vezzali et al., 2015), presumably due to the moderating effect of identification with a tolerant main character (Gabriel \& Young, 2011). Indeed, exposure to fiction in general is positively associated with social ability (for example through the adoption of other perspectives), whilst frequently reading non-fiction (in which social relationships are typically lacking) is negatively associated with social ability (though see Kidd \& Castano, 2019; Mar et al., 2006). Parasocial relationships can have detrimental consequences when particularly intense however: in college students, the intensity of emotional involvement with a media figure (during adolescence) was associated with less favorable perceptions of a current romantic partner and lower relationship satisfaction (Tukachinsky \& Dorros, 2018). In anxious older adults, it was found that the intensity of parasocial relations was associated with increased depressive symptoms, but only for those adults with low-quality parent-child relationships (Bernhold \& Metzger, 2020). Such negative effects of engagement with fiction may be exacerbated by media addiction and dependency (McCutcheon et al., 2002).

The bonding and social needs function of imaginative and narrative simulation overlaps with the social function of autobiographical memory, in which reminiscing and sharing of memories is used to develop, maintain, and nurture social bonds and social networks (Bluck et al., 2005); the function of transportation into media to satisfy the need for connectedness and a sense of belonging, through feelings of familiarity with and connection to the fictional characters through parasocial relationships (Green et al., 2004). Through imaginative and narrative simulation, individuals are able to take on various roles and identities within communities and cultures (Tay et al., 2018).This function forms the basis of the social glue theory of fiction, whereby fiction is conceptualised as a way to convey and reinforce common values (Gottschall, 2012). Moreover, constructive storytelling combined with social memory biases may lead to the emergence of collective memories and a shared reality, as well as shared norms, beliefs and ideologies, which fosters group identity, social bonds, and feelings of belonging and community between individuals (Bietti et al., 2019). 


\subsection{Identity and worldviews}

Simulation through narrative is at the foundation of our identities and worldviews (Singer \& Blagov, 2004). Narrative thought creates a coherent concept of the self by bringing together an individual's remembered past, experienced present, and anticipated future (McAdams, 2001). Narrative identities represent the dominant themes and concerns in people's lives, and are crucial for psychological wellbeing (Adler et al., 2016), for example by imparting a sense of meaning and purpose (Sumner et al., 2015). This also extends to future selves: mental representations of highly significant future events (e.g., caring for a newborn baby) provide core information for one's understanding of self, and support personal identity (e.g., a new mother, D'Argembeau et al., 2012; Rathbone et al., 2011).

Fiction subtly shapes identity and worldviews through a variety of processes, such as prompting reflection on the (un)desirability of character traits and values in oneself and others, and ways to change them (Tay et al., 2018). Such reflective engagement with fiction can lead to an improved self-concept with enhanced meaning and purpose (Ivey \& Johnston, 2013), but can also contribute to one's worldview, morality, and understanding of norms and values (Scalise Sugiyama, 2001). Indeed, simulation as a result of fiction has been suggested to cultivate and reinforce our moral decision-making faculty, enhancing our attention to better notice and respond to moral situations (Nussbaum, 1998). The simulation allows us to imaginatively apprehend what other people might be like, thus fostering empathy and a more inclusive range of moral values (Rorty \& Richard, 1989), as well as the likely consequences of certain decisions, and therefore contribute to what the right actions to do are (praxeology), and by extension, overall value systems and worldviews (Currie, 1995) ${ }^{1}$. Morality can in turn contribute to wellbeing through a sense of a coherent identity and self-worth (Hofmann et al., 2018), especially when these moral values (and sense of purpose) are shared within a group one identifies with (Brown et al., 2021; Graham \& Haidt, 2010).

The identity and worldview function of imaginative and narrative simulation finds similarities to the self function of autobiographical memory, in which memory is used to construct and support one's self-concept and identity, including the continuity of the self, which in turn facilitates a sense of purpose and meaning across time (Bluck et al., 2005); and the function of transportation into that allows for transformation and identity play, or the exploring and experimenting with other possible selves, who the individuals might become, wish to become or fear becoming (Green et al., 2004). This function captures reflectiveness, or the intentional, cognitive-emotional process for developing, reinforcing, or discarding one's habits, character, values, or worldview (Tay et al., 2018). Alternatively, narrative fiction may be

\footnotetext{
${ }^{1}$ A problem here might be imaginative resistance, or the idea that individuals are reluctant (whether unable or unwilling) to enter into imaginary worlds that condone moral standpoints we fundamentally disagree with (e.g., that murder is acceptable) (Gendler, 2006). If that idea holds, then at its most extreme, we would never learn new morals beyond our prior viewpoint from fiction, as we would simply refuse to engage with them. See for a discussion of this puzzle, Landy (2008).
} 
used to deceive or manipulate the audience to form coalitions and compete with conspecifics, which would also contribute to the fitness of the narrator (Bietti et al., 2019; see also Scalise Sugiyama, 1996).

\section{Imaginative and narrative simulation during the COVID-19 pandemic}

It is clear that the COVID-19 pandemic is a mental health crisis: there has been a proliferation of studies demonstrating ill effects of the pandemic and its associated restrictions since the beginning of the pandemic (the Dimensions app (https://app.dimensions.ai/) suggests that more than 17,000 articles with "COVID-19" and "mental health" or "psychological health" or "psychological wellbeing" in their titles or abstracts have been published since the start of the pandemic). In this section, we will examine the effect of our four proposed categories of simulative functions of imagination and fiction on psychological health (positive and negative), and link these directly to the COVID-19 pandemic, either through demonstrated studies or suggested directions. We note that there is currently limited empirical research to directly investigate (the psychological effects of) imagination and fiction during the COVID-19 pandemic, but argue there is plenty of potential, and will put forward suggestions for future directions where applicable.

Imagination and fiction play an important role in planning and future thought, but who would, and could, routinely simulate preparing for something as unpredictable as a pandemic? The perhaps surprising answer is: Fans of horror films and "prepper" genres (e.g., alien-invasion, apocalyptic, and zombie films). Scrivner et al. (2020) found that past and current engagement with such fiction was associated with greater preparedness and psychological resilience in the COVID-19 pandemic. This preparedness constituted feeling mentally prepared, not being surprised, previously having imagined it may happen, being able to predict the course of events of the pandemic, and even knowing what items to buy $^{2}$. This study supports the idea that we use simulations, including those offered by fiction, to prepare for real-world events, and offers empirical support for the hypothesis that fiction may serve adaptive functions (Carroll, 2004; Clasen, 2019). The undead in a zombie movie may be implausible, but the interpersonal and societal upheavals depicted may still allow people to glean information about ecological, social, and psychological consequences of societal turmoil and collapse, and about the qualities of existence under a state of emergency (Scrivner et al., 2020). The afforded information may be novel: The realistic pandemic movie Contagion (2011), depicting a global outbreak of a respiratory virus, soared to the top of streaming lists at the beginning of the COVID-19 pandemic (Sutton, 2020), suggesting that people may look to fictional representations to understand and process situations that to them are unprecedented (Reis Filho, 2020; Scrivner, 2021a). Thus, pandemic-themed and similar fiction

\footnotetext{
${ }^{2}$ With the exception of toilet paper. However, as suggested by study author Coltan Scrivner, this may be because no prepper movies had predicted it.
} 
may be an important source of information in such unusual times (Davis, 2017; Doherty \& Giordano, 2020; Marchalik \& Petrov, 2020; Peters, 2021).

Another way in which future-oriented thought influences psychological wellbeing is through planning rewarding activities. Social reinforcement theory (Lewinsohn, 1974) suggests that mood reductions that are a result of difficult life experiences (e.g., job loss) are associated with a reduction in rewarding activities. This in turn is associated with maintenance of negative mood or even further reductions, culminating in a vicious cycle. A treatment based on this theory is behavioral activation, which involves the monitoring and planning of rewarding (e.g., pleasant and/or meaningful) activities. A recent study has investigated how such future activity planning can influence psychological wellbeing during the pandemic, as well as how detailed imagination of carrying out activities can have a similar effect (Hoyer et al., 2021). A large sample of German participants engaged in a quasi-experimental study involving the behavioral task (100\% of participants) and an imaginary behavioral task (71\% of participants) and completed measures of affect and mood. The authors found that both selecting and imagining rewarding activities led to improved mood, both for positive and negative affect, though the effect was much bigger for negative affect, indicating this task could be particularly useful as an intervention for mental health problems. Moreover, the imagination task had a larger effect on positive affect than the standard behavioral task, indicating the usefulness of a task involving imagination.

For most, the COVID-19 pandemic is a tumultuous time, which entails living with constant instability and threats (of infection, of losing one's job, etc.) and not knowing what will come next. Fiction may be a safe way to engage in anticipatory problem-solving, by allowing for an exploration of potential risky scenarios without having to act them out oneself. Interestingly, dealing with threat appears to increase creativity (Riley \& Gabora, 2012), something which has been demonstrated during the COVID-19 pandemic as a response to increased death reflection but not death anxiety (Takeuchi et al., 2021). Like post-traumatic growth, reflection, a type of narrative processing, may help individuals cope with difficult situations, as opposed to becoming overwhelmed by, and reacting to, complex emotions arising from the situation.

During times of unrest and anxiety about the future (e.g., unpleasant states with high arousal), but also long periods of boredom (e.g., unpleasant states with low arousal) during lockdowns in the COVID19 pandemic, fiction may also be particularly useful as a tool for mood regulation (Mar et al., 2011; Reinecke \& Oliver, 2017). Comedic fiction, for instance, may be a welcome counterbalance to an existence that is anxiety-filled (Wellenzohn et al., 2016). Similarly, feel-good stories provide imaginative transportation into a world free of the threats that may be troubling readers and viewers in the real world, and may thus provide relief from noxious emotions (Reinecke \& Oliver, 2017). Yet even emotioncongruent entertainment, such as scary stories sought out during a time of anxiety, can provide for people 
an occasion for facing and mastering negative emotions (Doherty \& Giordano, 2020), which may be difficult to overcome when they are prompted by real-world events outside of one's control, as suggested by preliminary data (Scrivner, 2021b). Watching "prepper films" allows the audience to practice effective coping strategies that can be beneficial in real-world situations (Scrivner et al., 2020); even in unusual situations such as pandemics, where an increased feeling of preparedness and a reduced feeling of surprise may contribute to psychological well-being (Carleton, 2016). Likewise, horror films may afford audiences an opportunity for practicing emotional regulation to keep their fear and anxiety responses at a tolerable level (Clasen et al., 2020).

Indeed, in a qualitative study of semi-structured interviews with fifteen Italians who watched epidemic-themed films or TV series during the COVID-19 pandemic (Testoni et al., 2021) it was found that the main self-reported reasons for watching this fiction fell broadly within the following themes: (1) the need to reduce the uncertainty felt during the spread of the virus and the lockdown period by gathering information about epidemics (including what to do now and in the future); (2) the need to diminish anxiety, in particular through the knowledge that the film or TV series are fictional, are predictable, and often have a good ending (at least for the protagonists); (3) the desire to find a character with which they could identify (in particular a surviving protagonist), especially in fiction that was very similar to their own experiences, so that they would feel less lonely and engage in a positive reappraisal of their experience or at least parts of it; and (4) participants simply came across films or TV-series with a pandemic theme and were intrigued given the striking resemblance with real life (this reason was often associated with less positive effects on psychological wellbeing, and in fact at times made the participants feel anger and reduced hope for the future). These reasons all speak to using fiction as a way of understanding the complex and uncertain situation unfolding around oneself better (Davis, 2017), with a helpful detachment from reality, which allows for multiple perspectives, an exploration without risk of physical harm, and a detached, calmer engagement with one's emotions. Engaging with fiction this way helped with both positive reappraisal of past and present events (contributing to coping) and increased feeling of preparedness as the viewers have a better idea of actions they could take. Nonetheless, some also experienced negative emotions such as anxiety and reduced feelings of hope, as the pandemicthemed fiction also highlighted negative sides of human behavior and other negative consequences and events during pandemics. This issue may be heightened by the fact that many films around infectious diseases are highly scientifically inaccurate (Pappas et al., 2003).

During the COVID-19 pandemic, many are isolating at home with reduced opportunities for socializing. Social isolation can be painful and potentially harmful (Hawkley \& Cacioppo, 2010), and simulated social contact may be preferable to no engagement with people at all. Moreover, the pandemic has led to an increase in hostility towards some groups (Russell, 2020; Tessler et al., 2020), and given 
past research, imagined contact may be a way to assist in increasing empathy and decreasing hostility. Moreover, past research has shown that engagement with fictional films can increase behavioral intentions in difficult situations (e.g., climate change catastrophes) through an increased sense of personal obligation to act (Bilandzic \& Sukalla, 2019) - not through direct conveying of norms, but instead through the vicarious experience of other people's difficult fates, as well as a lack of explicit narrative persuasion, which allows for immersion into the story world whatever one's (prior) convictions.

Despite the potential of imagination and fiction on psychological wellbeing through bonding and attending other social needs, as well as a potential increased adherence to COVID-19 guidelines through increased empathy for others and an increased sense of responsibility, little research has been done on this function during the COVID-19 pandemic. Indeed, given that the pandemic has led to an externally imposed global deficit in socialization, previous research focusing on internal deficits can be extended to large samples cross-culturally (Jarzyna, 2020). In one such study, Fitzgerald et al. (2021) predicted that during social distancing, individuals who scored highly on transportability, or the ability to engage deeply with stories through mental and emotional immersion into a story world (Green et al., 2004), would seek out entertainment media for mood regulation (increasing positive feelings and alleviating negative feelings) for example through feelings of belongingness from parasocial relationships. Results indicated that the use of entertainment media increased from before to during social distancing, but that its use was associated with negative emotional states. More specifically they found that especially in older adults scoring highly on transportability, greater entertainment media use was associated with more negative moods, contrary to their hypothesis. It is unclear however whether media use contributed to the negative feelings, or whether individuals who had negative moods were more likely to seek out entertainment media. They also did not have data on the specific media content.

There have been increases in pandemic-themed media (Sutton, 2020) as well as familiar, nostalgic content (MRC Data, 2020a) during the COVID-19 pandemic, and it may be that while pandemic-themed media allows one to engage in problem-focused coping (including positive reappraisal), familiar content mostly serves as escapism or distraction, which is a type of emotion-focused coping that, like denial, is associated with less favorable effects on psychological wellbeing (Folkman \& Moskowitz, 2000). This suggestion is supported by the second MRC data release, which suggests that individuals are using entertainment more as escape, to take their minds off the current situation (both through past favorites and new content), and they are using entertainment less to be informed, as they are growing tired of hearing about the pandemic (MRC Data, 2020b). However, even escapist, emotion-focused coping strategies can be functional (short-term) strategies, by temporarily reducing stress and anxiety, which in turn can assist with subsequent problem-focused coping (Halfmann \& Reinecke, 2021). Thus, investigating whether levels of fiction consumption, including types of fiction consumed, have changed since before the 
pandemic, could be greatly interesting for further understanding of the functions of fiction during pandemics, in particular when relating to changes in psychological wellbeing through longitudinal correlational research or specific interventions.

The constant lack of stability and changes beyond one's own control during the COVID-19 pandemic has affected people's sense of a coherent self and identity (Godinic et al., 2020), and added moral injury, or psychological distress resulting from (in)actions that violate someone's moral or ethical code (Litam \& Balkin, 2021), and more directly, collective identity trauma-a direct threat to one's identity via severe discrimination — has contributed to reduced wellbeing in some (Kira et al., 2021). Narrative life reflection during the pandemic has been found to contribute to emotion regulation, finding purpose, and seeing parallels with previous life events (Lind et al., 2021), and by making sense of what is happening (Fioretti et al., 2020; Venuleo et al., 2020). Fiction - through its use of narrative reflection may have similar effects, though this has, to our knowledge, not been directly investigated in the context of the COVID-19 pandemic.

Narrative techniques and features that make fiction particularly compelling can also be exploited however, such as by conspiracy theories (Raab et al., 2013; Tangherlini et al., 2020). There has been a proliferation of conspiracy theories during the pandemic (YouGov, 2020), which explain what is happening through simple explanations for complex situations (e.g., major world events are caused by small, secret groups of powerful people) and provide a sense of identity (e.g., the believers are a group of people who see what is 'really' going on). Given the threat and uncertainty that the pandemic brings, this proliferation is unsurprising, but can have disastrous consequences, including the destruction of 5G cell towers and vaccine hesitancy, but also on psychological wellbeing, such as increased levels of anxiety and stress (van Mulukom et al., 2020). However, the direction of the effects of conspiracy beliefs is still not completely clear: It may be that people who score highly on anxiety and stress are more likely to seek out conspiracy theories to cope with their ill feelings, or that belief in conspiracy theories increases anxiety and stress, for example through increased perceived threat. Either way, elucidating how conspiracy theories exploit narrative techniques may be a good step to examining how these detrimental worldviews can be debunked and countered.

Though traditionally, conspiracy belief research has focused on cognitive and socio-existential factors predicting belief, more recent research has focused on the entertainment value of conspiracy beliefs, or the extent to which people appraise the conspiracy theory as interesting, exciting, and attentiongrabbing (van Prooijen et al., 2021). The authors point out that conspiracy theories are narratives that typically include mystery, suspected danger, and unknown forces - much like detective novels and scary films - and thus may carry entertainment value, which in turn can contribute to the believability of narrative (in line with fluency heuristics). It also puts a different spin on the association of anxiety and 
conspiracy belief: Like watching horror movies, some (e.g., sensation seekers) might actually seek out the anxiety that comes with uncertainty and perceived threat, especially if the experience includes a conclusion of some kind (e.g., the ending of a horror movie, or the resolution a conspiracy theory offers). Van Prooijen et al.'s (2021) multi-study research confirmed that conspiracy theories do have entertainment value, and that this influences belief in such theories. Given that the COVID-19 pandemic has been a time of both high arousal (high uncertainty and threat) and low arousal (long periods of boredom during the multiple lockdowns), investigating the entertainment value of conspiracy theories and its effects on psychological wellbeing could be an important next step.

The COVID-19 pandemic brought with it many regulations enforced worldwide in an attempt to stop the virus from spreading, as well as a new vaccination programme in order to prevent illness and death. In a perhaps somewhat unexpected turn of events, rather than these actions being welcomed by all, some have resisted taking part in these healthcare measures, triggered by what they perceive as an attack on their worldviews (e.g., freedom to refuse wearing a mask and getting a vaccine) and moral values (e.g., what actions are right). To our knowledge, there have not been studies investigating the role of imagination and fiction on moral values during the COVID-19 pandemic, but conspiracy theories are of course narratives with stronger connections to moral values and identity (REF), and directly influence behavior and intentions (REF). Moreover, previous research suggests that exposure to fictional films, especially those that are particularly engaging but do not carry explicit persuasive content, may be particularly helpful in increasing personal norms and behavioral intentions to engage in actions for the greater good (Bilandzic \& Sukalla, 2019). The lack of explicit persuasion means that the film can reach more individuals, including those who may be defensive or opposed to pandemic regulations, or those who simply are fatigued by the pandemic and unwilling to engage in further major changes to their regular habits and daily life. Narrative engagement on the other hand makes sure that the audience is both cognitive and emotionally involved with the narrative, which was in Bilandzic \& Sukalla's (2019) study was associated with greater experience of guilty and stronger intentions to act afterwards.

\section{Discussion}

Imagination and fiction are ubiquitous in human lives (Gottschall, 2012), play a crucial role as a tool for meaning-making and coping (Carroll, 2020), and have been vital historically for conveying norms and information to ensure survival and social cohesion in hunter-gatherer bands (Scalise Sugiyama, 2001; Smith et al., 2017). Though imagination and fiction may connote ephemeral or even 'useless' activities, we suggest that both phenomena have been crucial for our species' success and continue to play important roles in human lives (see also van Mulukom \& Geertz, 2021), not least during the COVID-19 pandemic, 
which has been a difficult time for many. We argue that simulations in imagination and fiction provide us with information and experiences, thus supporting planning and future thought, coping and emotion regulation, bonding and social needs, and identity and worldviews, which in turn can bolster psychological wellbeing, though some potentially maladaptive effects have also been noted. Crucially, despite important possibilities, relatively few studies have been done so far on the role of imagination and fiction in the context of the COVID-19 pandemic, and some of those that have suffer from methodological shortcomings (e.g., Zabelina et al., 2021, which suffers from a conceptual conflation of intentional and unintentional imagination, and interpreting very small or insignificant effects).

The COVID-19 studies discussed in the present article demonstrated positive or neutral effects of imagination and fiction on psychological wellbeing within all four proposed functions of imaginative and narrative simulation. Though the framework puts forward four distinct functions of imaginative and narrative simulation, it has become clear throughout this article that often, the functions overlap and complement each other. Indeed, the functions are interrelated in that they provide information (about the physical and/or social world) obtained through simulation and narrative and transmitted through social learning, which can inform and support present or future emotions, thoughts, and behaviors. Any specific or distinct evolutionary histories, and which of the four functions may be particularly important in the specific context of the current pandemic or future catastrophes, remains to be seen. It will depend in particular on what kind of information the circumstances require (e.g., information supporting behavioral intentions regarding healthcare guidelines), and which aspects of psychological health will be most affected (e.g., lockdowns specifically affect the satisfaction of social needs). Thus, the answer to a question asked in a recent article examining fiction as adaptive simulation, "[i]if fiction is an adaptive simulation, what is it a simulation of?" (Morin et al., 2019, p. 2) - well, it depends. While we acknowledge that singular theories may be attractive for a number of reasons, we argue that a more comprehensive framework which acknowledges multiple functions may be in this case more appropriate.

Immersion into fiction, or the focused absorption into the experience, has been put forward as one of the main modes through which arts and humanities lead to positive effects on psychological wellbeing (Tay et al., 2018). Here, it was not captured by one of the functions of imagination and fiction - rather, it is considered to be an important moderator of the experiences (Green et al., 2004; van Mulukom \& Geertz, 2021): The more one is immersed into the fiction, the more the fiction might be enjoyed and lead to increased story-consistent beliefs and opinions (Green \& Brock, 2000) and increased behavioral intentions (Bilandzic \& Sukalla, 2019). As such, we suggest that immersion, whether measured as transportation, flow, absorption, or story world absorption, is an important moderator variable to consider in studies on the functions of imaginative and narrative simulation and its effect on psychological wellbeing. 
Throughout the discussed studies on psychological wellbeing, directionality has been an issue: It is unclear whether people seek fiction, narrative, or media engagement out because they experience low psychological wellbeing, or do they experience low psychological wellbeing as a result of the fiction, narrative, or media engagement? The solution for such issues is to run longitudinal or experimental studies, where greater control can be exerted over the variables and a direction of effect can be deduced. Sometimes this may elucidate an unexpected path: As previously mentioned, while problem-focused coping might have more positive effects, and emotion-focused coping more negative ones, on psychological wellbeing respectively, it may be that emotion-focused coping first clears the path for problem-focused coping to occur (Halfmann \& Reinecke, 2021). Therefore, timeline may be important. Attention was paid to timeline in the COVID-19 study by Eden et al. (2020), who made a distinction between acute and chronic stressors, with stress conceptualized as acute, situational perceived threat, and anxiety as more chronic and more general perceived threat. The authors found that, in a sample of American students experiencing lockdown, stressed students attempted to escape and avoid their stress through hedonic media use (i.e., primarily pleasure-seeking), which was associated with less positive affect and lower mental health, while students scoring high on anxiety engaged in more eudaimonic media use (i.e., concerned with existential questions of purpose in life, meaning, or moral values), which was associated with overall more positive affect (see also Oliver \& Raney, 2011). However, in this study, the researchers combined everything from television, to internet websites, social media, phone calls, instant messaging, video games, and, podcasts into a single measure of 'media', meaning it is difficult to say to what extent engagement with fictional media drove these effects-however, neither do we distinguish strictly between different types of fiction, such as films and TV series as compared to books, and we acknowledge that there may be differences among these media (Green et al., 2004). Nonetheless, Eden et al.'s (2020) study demonstrates that future research on fiction, narrative, or media engagement may also benefit from differentiating between acute and chronic stressors and types of media use and coping.

Other central research on the effects of media use on psychological wellbeing we have minimally engaged with is mood management theory (MMT; Zillmann \& Bryant, 1985; see for a review, Reinecke, 2017). MMT proposes that the goal of mood management is to maintain a good mood or alter a bad mood. The mechanisms for doing so focus on engaging in excitatory homoeostasis, or balancing arousal, through a number of mechanisms: choosing to engage in media that (i) increase or reduce arousal depending on its content (excitatory potential), (ii) allow for immersion to distract, suppress or focus on the current mood (absorption potential), (iii) does or does not overlap with current mood (semantic affinity), and (iv) has positive hedonic or affective value (e.g., comedies) rather than negative affective valence (e.g., dramas) (hedonic value). A main issue with this theory is its underlying assumption that self-exposure to media is motivated by hedonic purposes with the aim of mood optimisation, while here 
we have seen that media exposure can have adaptive functions that go beyond positive effects on psychological wellbeing (also, as noted by Green et al., 2004, even if transportation is a desired state, that does not mean that transportation into narrative worlds is inherently pleasant; it can also be sad or scary).

Extensions of MMT deal with this by including mood adjustment, which is the idea that a 'good' (i.e., pleasurable affective) mood is not always the most adaptive mood in every situation, and that individuals may choose their media on the basis of suitability for the situation (Knobloch, 2003). For an overview and review of media use and coping, including perspectives on stress and coping, mood management and emotion regulation, and media addiction and problematic media use, see Wolfers and Schneider (2021).

One aspect of future research that we have only touched upon involves practical applications: simulation may be a useful prevention or intervention tool for the negative effects of COVID-19 lockdowns (and similar future situations) on psychological wellbeing (though see IJzerman et al., 2020). It may assist with preparing for the future, mental health, and social isolation, amongst other things, all from the comfort of one's home. Such prevention or intervention could be applied in a low-cost and pleasurable way (e.g., through engagement with fiction). Previous research on cognitive bibliotherapy (therapeutic exposure to verbal art) has suggested a beneficial, long-term effect on mild to moderate depression (see also Poerio \& Totterdell, 2020; Smith et al., 1997). For an overview and discussion of such therapeutic interventions, including expressive writing, therapeutic storytelling, bibliotherapy, poetry therapy, see McArdle and Byrt (2001). On the basis of the non-clinical research discussed here, it appears that there is at least some potential for practical applications of imagination and fiction for future situations like the current COVID-19 pandemic.

We conclude that engaging in imaginative and narrative simulation appears beneficial as lockdowns last; the structured and immersive process simulation such as provided by fiction may be particularly desirable. Given the vital role played by the arts and entertainment more broadly in almost all people's lives, much more empirical research should be dedicated to their psychological, social, and cultural effects and functions (Goldstein \& Bloom, 2011), not least in the context of large-scale catastrophic events such as pandemics: if not for the current pandemic, then for future occurrences of catastrophes.

\section{Conflict of Interest}

The authors declare that the research was conducted in the absence of any commercial or financial relationships that could be construed as a potential conflict of interest. 


\section{Author Contributions}

V.v.M. conceived of the idea for the study and discussed it with M.C. V.v.M. wrote the first draft of the article. M.C. provided feedback on the first draft and wrote the second draft of the article. V.v.M. wrote the final draft of the article, and initiated the revision of the article. V.v.M. and M.C. both approve the final version.

\section{Funding}

M.C.'s work is supported by grant no. 0132-00204B from the Independent Research Fund Denmark.

\section{References}

Adler, J. M., Lodi-Smith, J., Philippe, F. L., \& Houle, I. (2016). The incremental validity of narrative identity in predicting well-being: A review of the field and recommendations for the future. Personality and Social Psychology Review, 20(2), 142-175. https://doi.org/10.1177/1088868315585068

Aspinwall, L. G., \& Taylor, S. E. (1997). A stitch in time: Self-regulation and proactive coping. Psychological bulletin, 121(3), 417-436. https://doi.org/10.1037/0033-2909.121.3.417

Barsalou, L. W. (2009). Simulation, situated conceptualization, and prediction. Philosophical transactions of The Royal Society B: biological sciences, 364(1521), 1281-1289. https://doi.org/10.1098/rstb.2008.0319

Bartlett, F. C. (1932). Remembering: A study in experimental and social psychology. Cambridge University Press.

Bernhold, Q. S., \& Metzger, M. (2020). Older adults' parasocial relationships with favorite television characters and depressive symptoms. Health Communication, 35(2), 168-179. https://doi.org/10.1080/10410236.2018.1548336

Biesele, M. (1986). How hunter-gatherers' stories" make sense": Semantics and adaptation. Cultural anthropology, 1(2), 157-170. 
Bietti, L. M., Tilston, O., \& Bangerter, A. (2019). Storytelling as adaptive collective sensemaking. Topics in cognitive science, 11(4), 710-732. https://doi.org/10.1111/tops.12358

Bilandzic, H., \& Sukalla, F. (2019). The role of fictional film exposure and narrative engagement for personal norms, guilt and intentions to protect the climate. Environmental Communication, 13(8), 1069-1086. https://doi.org/10.1080/17524032.2019.1575259

Bluck, S., Alea, N., Habermas, T., \& Rubin, D. C. (2005). A tale of three functions: The selfreported uses of autobiographical memory. Social cognition, 23(1), 91-117. https://doi.org/10.1521/soco.23.1.91.59198

Brown, D. E. (1991). Human Universals. McGraw-Hill.

Brown, J. E., van Mulukom, V., Charles, S. J., \& Farias, M. (2021). Do you need religion to enjoy the benefits of Church services? Social bonding, morality and quality of life among religious and secular congregations. Psychology of Religion and Spirituality. https://doi.org/10.1037/rel0000447

Bruner, J. S. (1986). Actual minds, possible worlds. Harvard University Press.

Bruner, J. S. (2002). Making stories: Law, literature, life. Harvard University Press.

Bulley, A., Redshaw, J., \& Suddendorf, T. (2020). The Future-Directed Functions of the Imagination: From Prediction to Metaforesight. In A. Abraham (Ed.), The Cambridge Handbook of the Imagination (pp. 425-443). https://doi.org/10.1017/9781108580298.026

Carleton, R. N. (2016). Fear of the unknown: One fear to rule them all? Journal of anxiety disorders, 41, 5-21. https://doi.org/10.1016/j.janxdis.2016.03.011

Carroll, J. (2004). Literary Darwinism: Evolution, human nature, and literature. Routledge. 
Carroll, J. (2020). Imagination, the Brain's Default Mode Network, and Imaginative Verbal Artifacts. In J. Carroll, M. Clasen, \& E. Jonsson (Eds.), Evolutionary Perspectives on Imaginative Culture (pp. 31-52). Springer.

Clark, A. (2015). Surfing uncertainty: Prediction, action, and the embodied mind. Oxford University Press.

Clasen, M. (2019). Imagining the End of the World: A Biocultural Analysis of Post-Apocalyptic Fiction. In D. Vanderbeke \& B. Cooke (Eds.), Evolution and Popular Narrative (pp. 6482). Brill. https://doi.org/10.1163/9789004391161_005

Clasen, M., Kjeldgaard-Christiansen, J., \& Johnson, J. A. (2020). Horror, Personality, and Threat Simulation: A Survey on the Psychology of Scary Media. Evolutionary Behavioral Sciences, 14(3), 213-230. https://doi.org/10.1037/ebs0000152

Coe, K., Aiken, N. E., \& Palmer, C. T. (2006). Once upon a time: Ancestors and the evolutionary significance of stories. Anthropological Forum, 16(1), 21-40. https://doi.org/10.1080/00664670600572421

Crisp, R. J., \& Turner, R. N. (2009). Can imagined interactions produce positive perceptions?: Reducing prejudice through simulated social contact. American psychologist, 64(4), 231240. https://doi.org/10.1037/a0014718

Currie, G. (1995). The moral psychology of fiction. Australasian Journal of Philosophy, 73(2), 250-259.

D'Argembeau, A., Lardi, C., \& Van der Linden, M. (2012). Self-defining future projections: Exploring the identity function of thinking about the future. Memory, 20(2), 110-120. https://doi.org/10.1080/09658211.2011.647697

Da Silva, S. G., \& Tehrani, J. J. (2016). Comparative phylogenetic analyses uncover the ancient roots of Indo-European folktales. Royal Society open science, 3(1), 150645. https://doi.org/10.1098/rsos.150645 
Dal Cin, S., Zanna, M. P., \& Fong, G. T. (2004). Narrative persuasion and overcoming resistance. In E. S. Knowles \& J. A. Linn (Eds.), Resistance and persuasion (pp. 175191). Erlbaum.

Davis, M. (2017). "Is it Going to be Real?" Narrative and Media on a Pandemic. Qualitative Social Research, 18(1), 1-19. https://doi.org/10.17169/fqs-18.1.2768

De Brigard, F., Addis, D. R., Ford, J. H., Schacter, D. L., \& Giovanello, K. S. (2013). Remembering what could have happened: Neural correlates of episodic counterfactual thinking. Neuropsychologia, 51(12), 2401-2414. https://doi.org/10.1016/i.neuropsychologia.2013.01.015

Derrick, J. L., Gabriel, S., \& Hugenberg, K. (2009). Social surrogacy: How favored television programs provide the experience of belonging. Journal of Experimental Social Psychology, 45(2), 352-362. https://doi.org/10.1016/j.jesp.2008.12.003

Derrick, J. L., Gabriel, S., \& Tippin, B. (2008). Parasocial relationships and self-discrepancies: Faux relationships have benefits for low self-esteem individuals. Personal relationships, 15(2), 261-280. https://doi.org/10.1111/j.1475-6811.2008.00197.x

Djikic, M., Oatley, K., Zoeterman, S., \& Peterson, J. B. (2009). Defenseless against art? Impact of reading fiction on emotion in avoidantly attached individuals. Journal of Research in Personality, 43(1), 14-17. https://doi.org/10.1016/j.jrp.2008.09.003

Doherty, J., \& Giordano, J. (2020). What we may learn-and need-from pandemic fiction. Philosophy, Ethics, and Humanities in Medicine, 15(1), 4. https://doi.org/10.1186/s13010-020-00089-0

Eden, A. L., Johnson, B. K., Reinecke, L., \& Grady, S. M. (2020). Media for coping during COVID-19 social distancing: stress, anxiety, and psychological well-being. Frontiers in Psychology, 11, 3388. https://doi.org/10.3389/fpsyg.2020.577639

Eyal, K., \& Te'eni-Harari, T. (2013). Explaining the relationship between media exposure and early adolescents' body image perceptions. Journal of Media Psychology, 25, 129-141. https://doi.org/10.1027/1864-1105/a000094 
Fioretti, C., Palladino, B. E., Nocentini, A., \& Menesini, E. (2020). Positive and Negative Experiences of Living in COVID-19 Pandemic: Analysis of Italian Adolescents' Narratives. Frontiers in Psychology, 11, 3011. https://doi.org/10.3389/fpsyg.2020.599531

Fitzgerald, K., Yue, Z., Wong, J. C. S., \& Green, M. C. (2021). Entertainment and social media use during social distancing: Examining trait differences in transportability and need for social assurance. Psychology of Popular Media. https://doi.org/10.1037/ppm0000365

Folkman, S., \& Moskowitz, J. T. (2000). Stress, positive emotion, and coping. Current Directions in Psychological Science, 9(4), 115-118. https://doi.org/10.1111/1467$\underline{8721.00073}$

Fuentes, A. (2020). The Evolution of a Human Imagination. In A. Abraham (Ed.), The Cambridge Handbook of the Imagination (pp. 13-29).

Gabriel, S., \& Young, A. F. (2011). Becoming a Vampire Without Being Bitten. Psychological science, 22(8), 990-994. https://doi.org/10.1177/0956797611415541

Gendler, T. S. (2006). Imaginative resistance revisited. In S. Nichols (Ed.), The architecture of the imagination: New essays on pretence, possibility, and fiction (pp. 149-173). Oxford University Press.

Giles, D. (2012). Parasocial relationships: Current Directions in Theory and Method. In H. Bilandzic, G. Patriarche, \& P. J. Traudt (Eds.), The social use of media: Cultural and social scientific perspectives on audience research (pp. 161-176). Intellect.

Godinic, D., Obrenovic, B., \& Khudaykulov, A. (2020). Effects of economic uncertainty on mental health in the COVID-19 pandemic context: social identity disturbance, job uncertainty and psychological well-being model. International Journal of Innovation and Economic Development, 6, 61-74. https://doi.org/10.18775/ijied.1849-7551$\underline{7020.2015 .61 .2005}$

Goldstein, T. R., \& Bloom, P. (2011). The mind on stage: why cognitive scientists should study acting. Trends in Cognitive Sciences, 15(4), 141-142. https://doi.org/10.1016/j.tics.2011.02.003 
Gottschall, J. (2012). The storytelling animal: How stories make us human. Houghton Mifflin Harcourt.

Graham, J., \& Haidt, J. (2010). Beyond beliefs: Religions bind individuals into moral communities. Personality and Social Psychology Review, 14(1), 140-150. https://doi.org/10.1177/1088868309353415

Green, M. C., \& Brock, T. C. (2000). The role of transportation in the persuasiveness of public narratives. Journal of personality and social psychology, 79(5), 701-721. https://doi.org/10.1037/0022-3514.79.5.701

Green, M. C., Brock, T. C., \& Kaufman, G. F. (2004). Understanding media enjoyment: The role of transportation into narrative worlds. Communication theory, 14(4), 311-327. https://doi.org/10.1111/j.1468-2885.2004.tb00317.x

Groarke, J. M., Berry, E., Graham-Wisener, L., McKenna-Plumley, P. E., McGlinchey, E., \& Armour, C. (2020). Loneliness in the UK during the COVID-19 pandemic: Crosssectional results from The COVID-19 Psychological Wellbeing Study. PLoS One, 15(9), e0239698. https://doi.org/10.1371/journal.pone.0239698

Grupe, D. W., \& Nitschke, J. B. (2013). Uncertainty and anticipation in anxiety: an integrated neurobiological and psychological perspective. Nature Reviews Neuroscience, 14(7), 488-501. https://doi.org/10.1038/nrn3524

Halfmann, A., \& Reinecke, L. (2021). Binge-watching as case of escapist entertainment use. In P. Vorderer \& C. Klimmt (Eds.), The Oxford Handbook of Entertainment Theory (pp. 181-203). Oxford University Press).

Hamilton, J. P., Furman, D. J., Chang, C., Thomason, M. E., Dennis, E., \& Gotlib, I. H. (2011). Default-mode and task-positive network activity in major depressive disorder: implications for adaptive and maladaptive rumination. Biological psychiatry, 70(4), 327 333. https://doi.org/10.1016/j.biopsych.2011.02.003 
Hawkley, L. C., \& Cacioppo, J. T. (2010). Loneliness Matters: A Theoretical and Empirical Review of Consequences and Mechanisms. Annals of Behavioral Medicine, 40(2), 218227. https://doi.org/10.1007/s12160-010-9210-8

Higgins, E. T. (1989). Self-discrepancy theory: What patterns of self-beliefs cause people to suffer? In L. Berkowitz (Ed.), Advances in experimental social psychology (Vol. 22, pp. 93-136). Elsevier.

Hofmann, W., Brandt, M. J., Wisneski, D. C., Rockenbach, B., \& Skitka, L. J. (2018). Moral punishment in everyday life. Personality and Social Psychology Bulletin, 44(12), 16971711. https://doi.org/10.1177/0146167218775075

Hoyer, J., Dechmann, J. C. G., Stender, T., \& Čolić, J. (2021). Selecting and imagining rewarding activities during the COVID-19 lockdown: Effects on mood and what moderates them. International Journal of Psychology. https://doi.org/10.1002/ijop.12759

IJzerman, H., Lewis, N. A., Przybylski, A. K., Weinstein, N., DeBruine, L., Ritchie, S. J., Vazire, S., Forscher, P. S., Morey, R. D., \& Ivory, J. D. (2020). Use caution when applying behavioural science to policy. Nature Human Behaviour, 4(11), 1092-1094. https://doi.org/10.1038/s41562-020-00990-w

Ivey, G., \& Johnston, P. H. (2013). Engagement with young adult literature: Outcomes and processes. Reading research quarterly, 48(3), 255-275. https://doi.org/10.1002/rrq.46

Jarzyna, C. L. (2020). Parasocial Interaction, the COVID-19 Quarantine, and Digital Age Media. Human Arenas, 1-17. https://doi.org/10.1007/s42087-020-00156-0

Kidd, D., \& Castano, E. (2019). Reading literary fiction and theory of mind: Three preregistered replications and extensions of Kidd and Castano (2013). Social Psychological and Personality Science, 10(4), 522-531. https://doi.org/10.1177/1948550618775410

Killingsworth, M. A., \& Gilbert, D. T. (2010). A wandering mind is an unhappy mind. Science, 330(6006), 932-932. https://doi.org/10.1126/science.1192439 
Kira, I. A., Shuwiekh, H. A., Alhuwailah, A., Ashby, J. S., Sous Fahmy Sous, M., Baali, S. B. A., Azdaou, C., Oliemat, E., \& Jamil, H. J. (2021). The effects of COVID-19 and collective identity trauma (intersectional discrimination) on social status and well-being. Traumatology, 27 (1), 29-39. https://doi.org/10.1037/trm0000289

Knobloch, S. (2003). Mood adjustment via mass communication. Journal of Communication, 53(2), 233-250. https://doi.org/10.1111/j.1460-2466.2003.tb02588.x

Landy, J. (2008). A nation of Madame Bovarys: On the possibility and desirability of moral improvement through fiction. In G. L. Hagberg (Ed.), Art and ethical criticism (pp. 6394). Blackwell.

Lewinsohn, P. M. (1974). Clinical and theoretical aspects of depression. In K. S. Calhoun, H. E. Adams, \& K. M. Mitchel (Eds.), Innovative treatment methods in psychopathology (pp. 63-120). Wiley.

Lind, M., Bluck, S., \& McAdams, D. P. (2021). More Vulnerable? The Life Story Approach Highlights Older People's Potential for Strength During the Pandemic. The Journals of Gerontology: Series B, 76(2), e45-e48. https://doi.org/10.1093/geronb/gbaa105

Litam, S. D. A., \& Balkin, R. S. (2021). Moral injury in health-care workers during COVID-19 pandemic. Traumatology, 27(1), 14. https://doi.org/10.1037/trm0000290

Luyten, P., \& Fonagy, P. (2016). The self in depression. In M. Kyrios, R. Moulding, M. Nedeljkovic, S. S. Bhar, G. Doron, \& M. Mikulincer (Eds.), The self in understanding and treating psychological disorders (pp. 71-81). Cambridge University Press.

Mahr, J. B., \& Csibra, G. (2018). Why do we remember? The communicative function of episodic memory. Behavioral and Brain Sciences, 41, 1-93. https://doi.org/10.1017/S0140525X17000012

Mar, R. A., \& Oatley, K. (2008). The function of fiction is the abstraction and simulation of social experience. Perspectives on Psychological Science, 3(3), 173-192. https://doi.org/10.1111/j.1745-6924.2008.00073.x 
Mar, R. A., Oatley, K., Djikic, M., \& Mullin, J. (2011). Emotion and narrative fiction: Interactive influences before, during, and after reading. Cognition \& emotion, 25(5), 818-833. https://doi.org/10.1080/02699931.2010.515151

Mar, R. A., Oatley, K., Hirsh, J., dela Paz, J., \& Peterson, J. B. (2006). Bookworms versus nerds: Exposure to fiction versus non-fiction, divergent associations with social ability, and the simulation of fictional social worlds. Journal of Research in Personality, 40(5), 694-712. https://doi.org/10.1016/j.jrp.2005.08.002

Marchalik, D., \& Petrov, D. (2020). Seeing COVID-19 through José Saramago's Blindness. The Lancet, 395(10241), 1899. https://doi.org/10.1016/S0140-6736(20)31352-0

McAdams, D. P. (2001). The psychology of life stories. Review of general psychology, 5(2), 100-122. https://doi.org/10.1037/1089-2680.5.2.100

McArdle, S., \& Byrt, R. (2001). Fiction, poetry and mental health: expressive and therapeutic uses of literature. Journal of Psychiatric and Mental Health Nursing, 8(6), 517-524. https://doi.org/10.1046/j.1351-0126.2001.00428.x

McCutcheon, L. E., Lange, R., \& Houran, J. (2002). Conceptualization and measurement of celebrity worship. British Journal of Psychology, 93(1), 67-87. https://doi.org/10.1348/000712602162454

Miles, E., \& Crisp, R. J. (2014). A meta-analytic test of the imagined contact hypothesis. Group Processes \& Intergroup Relations, 17(1), 3-26. https://doi.org/10.1177/1368430213510573

Morin, O., Acerbi, A., \& Sobchuk, O. (2019). Why people die in novels: testing the ordeal simulation hypothesis. Palgrave Communications, 5(1), 1-10. https://doi.org/10.1057/s41599-019-0267-0

MRC Data. (2020a). COVID-19: Tracking the Impact on the Entertainment Landscape - Release 1. https://www.billboard.com/music/music-news/covid-19-tracking-the-impact-on-theentertainment-landscape-release-1-9355929/ 
MRC Data. (2020b). COVID-19: Tracking the Impact on the Entertainment Landscape - Release 2. https://www.billboard.com/music/music-news/covid-19-tracking-the-impact-on-theentertainment-landscape-release-2-9366516/

Nussbaum, M. C. (1998). Exactly and responsibly: A defense of ethical criticism. Philosophy and Literature, 22(2), 343-365.

Oatley, K., Keltner, D., \& Jenkins, J. M. (2006). Understanding emotions. Blackwell publishing.

Oliver, M. B., \& Raney, A. A. (2011). Entertainment as pleasurable and meaningful: Identifying hedonic and eudaimonic motivations for entertainment consumption. Journal of Communication, 61(5), 984-1004. https://doi.org/10.1111/j.1460-2466.2011.01585.x

Pappas, G., Seitaridis, S., Akritidis, N., \& Tsianos, E. (2003). Infectious diseases in cinema: virus hunters and killer microbes. Clinical Infectious Diseases, 37(7), 939-942. https://doi.org/10.1086/377740

Perner, J., \& Kühberger, A. (2005). Mental simulation. In B. F. Malle \& S. D. Hodges (Eds.), Other minds: How humans bridge the divide between self and others (pp. 174-189). Guilford Press.

Peters, M. A. (2021). Love and social distancing in the time of Covid-19: The philosophy and literature of pandemics. Educational Philosophy and Theory, 53(8), 755-759. https://doi.org/0.1080/00131857.2020.175009

Pham, L. B., \& Taylor, S. E. (1999). From thought to action: Effects of process-versus outcomebased mental simulations on performance. Personality and Social Psychology Bulletin, 25(2), 250-260. https://doi.org/10.1177/0146167299025002010

Pierce, M., Hope, H., Ford, T., Hatch, S., Hotopf, M., John, A., Kontopantelis, E., Webb, R., Wessely, S., \& McManus, S. (2020). Mental health before and during the COVID-19 pandemic: a longitudinal probability sample survey of the UK population. The Lancet Psychiatry, 7(10), 883-892. https://doi.org/10.1016/S2215-0366(20)30308-4 
Poerio, G., \& Totterdell, P. (2020). The effect of fiction on the well-being of older adults: a longitudinal RCT intervention study using audiobooks. Psychosocial Intervention, 29(1), 29-38. https://doi.org/10.5093/pi2019a16

Poerio, G. L., Totterdell, P., Emerson, L.-M., \& Miles, E. (2015). Love is the triumph of the imagination: Daydreams about significant others are associated with increased happiness, love and connection. Consciousness and Cognition, 33, 135-144.

https://doi.org/10.1016/j.concog.2014.12.011

Poerio, G. L., Totterdell, P., Emerson, L.-M., \& Miles, E. (2016). Helping the heart grow fonder during absence: Daydreaming about significant others replenishes connectedness after induced loneliness. Cognition and emotion, 30(6), 1197-1207. https://doi.org/10.1080/02699931.2015.1049516

Poerio, G. L., Totterdell, P., \& Miles, E. (2013). Mind-wandering and negative mood: Does one thing really lead to another? Consciousness and Cognition, 22(4), 1412-1421. https://doi.org/10.1016/i.concog.2013.09.012

Pyszczynski, T., \& Greenberg, J. (1987). Self-regulatory perseveration and the depressive selffocusing style: a self-awareness theory of reactive depression. Psychological bulletin, 102(1), 122-138.

Raab, M. H., Ortlieb, S., Auer, N., Guthmann, K., \& Carbon, C.-C. (2013). Thirty shades of truth: conspiracy theories as stories of individuation, not of pathological delusion. Frontiers in Psychology, 4, 406. https://doi.org/10.3389/fpsyg.2013.00406

Rathbone, C. J., Conway, M. A., \& Moulin, C. J. (2011). Remembering and imagining: The role of the self. Consciousness and Cognition, 20(4), 1175-1182. https://doi.org/10.1016/j.concog.2011.02.013

Reddan, M. C., Wager, T. D., \& Schiller, D. (2018). Attenuating neural threat expression with imagination. Neuron, 100(4), 994-1005. e1004. https://doi.org/10.1016/j.neuron.2018.10.047

Reinecke, L., \& Oliver, M. B. (2017). Media use and well-being: Status quo and open questions. In L. Reinecke \& M. B. Oliver (Eds.), The Routledge handbook of media use and well- 
being: International perspectives on theory and research on positive media effects (pp. 313). Routledge.

Reis Filho, L. (2020). No Safe Space: Zombie Film Tropes during the COVID-19 Pandemic. Space and Culture, 23(3), 253-258. https://doi.org/10.1177/1206331220938642

Riley, S., \& Gabora, L. (2012). Evidence that threatening situations enhance creativity. 34th Annual Meeting of the Cognitive Science Society, Sapporo, Japan.

Rorty, R., \& Richard, R. (1989). Contingency, irony, and solidarity. Cambridge University Press.

Russell, A. (2020). The rise of coronavirus hate crimes. The New Yorker, 17.

Scalise Sugiyama, M. (1996). On the origins of narrative. Human nature, 7(4), 403-425. https://doi.org/10.1007/BF02732901

Scalise Sugiyama, M. (2001). Food, Foragers, and Folklore: The Role of Narrative in Human Subsistence. Evolution and Human Behavior, 22(4), 221-240. https://doi.org/10.1016/S1090-5138(01)00063-0

Schacter, D. L., \& Addis, D. R. (2007). The cognitive neuroscience of constructive memory: remembering the past and imagining the future. Philosophical Transactions of the Royal Society of London B: Biological Sciences, 362(1481), 773-786. https://doi.org/10.1098/rstb.2007.2087

Schacter, D. L., Addis, D. R., \& Buckner, R. L. (2007). Remembering the past to imagine the future: the prospective brain. Nature Reviews Neuroscience, 8(9), 657-661. https://doi.org/10.1038/nrn2213

Scrivner, C. (2021a). An Infectious Curiosity: Morbid Curiosity and Media Preferences During a Pandemic. Evolutionary Studies in Imaginative Culture, 5(1), 1-12. https://doi.org/10.26613/esic/5.1.206 
Scrivner, C. (2021b). Why Horror Films Are More Popular Than Ever. Nautilus(95). https://nautil.us/issue/95/escape/why-horror-films-are-more-popular-than-ever

Scrivner, C., Johnson, J. A., Kjeldgaard-Christiansen, J., \& Clasen, M. (2020). Pandemic practice: Horror fans and morbidly curious individuals are more psychologically resilient during the COVID-19 pandemic. Personality and Individual Differences, 168, 110397. https://doi.org/10.1016/j.paid.2020.110397

Seli, P., Beaty, R. E., Marty-Dugas, J., \& Smilek, D. (2019). Depression, anxiety, and stress and the distinction between intentional and unintentional mind wandering. Psychology of Consciousness: Theory, Research, and Practice, 6(2), 163-170. https://doi.org/10.1037/cns0000182

Shanton, K., \& Goldman, A. (2010). Simulation theory. Wiley Interdisciplinary Reviews: Cognitive Science, 1(4), 527-538. https://doi.org/10.1002/wcs.33

Singer, J. A., \& Blagov, P. (2004). The Integrative Function of Narrative Processing: Autobiographical Memory, Self-Defining Memories, and the Life Story of Identity. In D. R. Beike, J. M. Lampinen, \& D. A. Behrend (Eds.), The self and memory (pp. 117-138). Psychology Press.

Smith, D., Schlaepfer, P., Major, K., Dyble, M., Page, A. E., Thompson, J., Chaudhary, N., Salali, G. D., Mace, R., Astete, L., Ngales, M., Vinicius, L., \& Migliano, A. B. (2017). Cooperation and the evolution of hunter-gatherer storytelling. Nature Communications, 8(1), 1853. https://doi.org/10.1038/s41467-017-02036-8

Smith, E. A. (2010). Communication and collective action: language and the evolution of human cooperation. Evolution and Human Behavior, 31(4), 231-245. https://doi.org/10.1016/j.evolhumbehav.2010.03.001

Smith, N. M., Floyd, M. R., Scogin, F., \& Jamison, C. S. (1997). Three-year follow-up of bibliotherapy for depression. Journal of Consulting and Clinical Psychology, 65(2), 324327. https://doi.org/10.1037/0022-006x.65.2.324 
Somer, E., Lehrfeld, J., Bigelsen, J., \& Jopp, D. S. (2016). Development and validation of the Maladaptive Daydreaming Scale (MDS). Consciousness and Cognition, 39, 77-91. https://doi.org/10.1016/j.concog.2015.12.001

Stawarczyk, D., \& D'Argembeau, A. (2015). Neural correlates of personal goal processing during episodic future thinking and mind-wandering: An ALE meta-analysis. Human brain mapping, 36(8), 2928-2947. https://doi.org/10.1002/hbm.22818

Suddendorf, T., \& Corballis, M. C. (2007). The evolution of foresight: What is mental time travel, and is it unique to humans? Behavioral and Brain Sciences, 30(3), 299-313. https://doi.org/10.1017/S0140525X07001975

Sumner, R., Burrow, A. L., \& Hill, P. L. (2015). Identity and purpose as predictors of subjective well-being in emerging adulthood. Emerging adulthood, 3(1), 46-54. https://doi.org/10.1177/2167696814532796

Sutton, K. (2020). Pandemic-Related Programming Surges on Netflix Amid Coronavirus Spread. Adweek. https://www.adweek.com/convergent-tv/pandemic-related-programming-surgeson-netflix-amid-coronavirus-spread/

Szpunar, K. K., Watson, J. M., \& McDermott, K. B. (2007). Neural substrates of envisioning the future. Proceedings of the National Academy of Sciences, 104(2), 642-647. https://doi.org/10.1073/pnas.0610082104

Takeuchi, R., Guo, N., Teschner, R. S., \& Kautz, J. (2021). Reflecting on death amidst COVID19 and individual creativity: Cross-lagged panel data analysis using four-wave longitudinal data. Journal of Applied Psychology, 106(8), 1156. https://doi.org/10.1037/apl0000949

Tangherlini, T. R., Shahsavari, S., Shahbazi, B., Ebrahimzadeh, E., \& Roychowdhury, V. (2020). An automated pipeline for the discovery of conspiracy and conspiracy theory narrative frameworks: Bridgegate, Pizzagate and storytelling on the web. PLoS One, 15(6), e0233879. https://doi.org/10.1371/journal.pone.0233879 
Tay, L., Pawelski, J. O., \& Keith, M. G. (2018). The role of the arts and humanities in human flourishing: A conceptual model. The Journal of Positive Psychology, 13(3), 215-225. https://doi.org/10.1080/17439760.2017.1279207

Taylor, M. (2013). The Oxford Handbook of the Development of Imagination. Oxford University Press.

Taylor, S. E., Pham, L. B., Rivkin, I. D., \& Armor, D. A. (1998). Harnessing the imagination: Mental simulation, self-regulation, and coping. American psychologist, 53(4), 429-439. https://doi.org/10.1037/0003-066X.53.4.429

Tessler, H., Choi, M., \& Kao, G. (2020). The Anxiety of Being Asian American: Hate Crimes and Negative Biases During the COVID-19 Pandemic. American Journal of Criminal Justice, 45, 636-646. https://doi.org/10.1007/s12103-020-09541-5

Testoni, I., Rossi, E., Pompele, S., Malaguti, I., \& Orkibi, H. (2021). Catharsis through cinema: An Italian qualitative study on watching tragedies to mitigate the fear of COVID-19. Frontiers in Psychiatry, 12, 622174. https://doi.org/10.3389/fpsyt.2021.622174

Tukachinsky, R., \& Dorros, S. M. (2018). Parasocial romantic relationships, romantic beliefs, and relationship outcomes in USA adolescents: rehearsing love or setting oneself up to fail? Journal of Children and Media, 12(3), 329-345. https://doi.org/10.1080/17482798.2018.1463917

Tulving, E. (1985). Memory and consciousness. Canadian Psychology/Psychologie canadienne, 26(1), 1-12. https://doi.org/10.1037/h0080017

van Mulukom, V. (2013). Imagining a Brave New Future: The Effects of Novelty and Plausibility on Episodic Simulation [Doctoral Thesis, The University of Auckland]. Auckland, New Zealand.

van Mulukom, V. (2019). The cognitive science of imagination and religion. Journal for the Cognitive Science of Religion, 5(1), 5-20. https://doi.org/10.1558/jcsr.39503 
van Mulukom, V., \& Geertz, A. (2021). The importance of imagination and subjective knowledge: The evolution of art and religion as symbolic representations of feelings, experiences, and beliefs. PsyArXiv. https://doi.org/10.31234/osf.io/7y6w8

van Mulukom, V., Muzzulini, B., Rutjens, B. T., Van Lissa, C. J., \& Farias, M. (2021). The Psychological Impact of Threat and Lockdowns During the COVID-19 Pandemic: Exacerbating Factors and Mitigating Actions. Translational Behavioral Medicine 11(7), 1318-1329. https://doi.org/10.1093/tbm/ibab072

van Mulukom, V., Pummerer, L., Alper, S., Bai, M. H., Čavojová, V., Farias, J. E. M., Kay, C. S., Lazarevic, L., Lobato, E. J., Marinthe, G., Pavela Banai, I., Šrol, J., \& Žeželj, I. (2020). Antecedents and consequences of COVID-19 conspiracy beliefs: a systematic review. PsyArXiv. https://doi.org/10.31234/osf.io/u8yah

van Prooijen, J. W., Ligthart, J., Rosema, S., \& Xu, Y. (2021). The entertainment value of conspiracy theories. British Journal of Psychology. https://doi.org/10.1111/bjop.12522

Venuleo, C., Marinaci, T., Gennaro, A., \& Palmieri, A. (2020). The meaning of living in the time of COVID-19. A large sample narrative inquiry. Frontiers in Psychology, 11, 577077. https://doi.org/10.3389/fpsyg.2020.577077

Vezzali, L., Capozza, D., Stathi, S., \& Giovannini, D. (2012). Increasing outgroup trust, reducing infrahumanization, and enhancing future contact intentions via imagined intergroup contact. Journal of Experimental Social Psychology, 48(1), 437-440. https://doi.org/10.1016/j.jesp.2011.09.008

Vezzali, L., Stathi, S., Giovannini, D., Capozza, D., \& Trifiletti, E. (2015). The greatest magic of Harry Potter: Reducing prejudice. Journal of Applied Social Psychology, 45(2), 105-121. https://doi.org/10.1111/jasp.12279

Wellenzohn, S., Proyer, R. T., \& Ruch, W. (2016). Humor-based online positive psychology interventions: a randomized placebo-controlled long-term trial. The Journal of Positive Psychology, 11(6), 584-594. https://doi.org/10.1080/17439760.2015.1137624 
Wiessner, P. W. (2014). Embers of society: Firelight talk among the Ju/'hoansi Bushmen. Proceedings of the National Academy of Sciences, 111(39), 14027-14035. https://doi.org/10.1073/pnas.1404212111

Wolfers, L. N., \& Schneider, F. M. (2021). Using media for coping: a scoping review. Communication Research, 48(8), 1210-1234. https://doi.org/10.1177/0093650220939778

YouGov. (2020). YouGov Cambridge Globalism 2020. https://docs.cdn.yougov.com/msvke1lg9d/Globalism2020\%20Guardian\%20Conspiracy\% 20Theories.pdf

Zabelina, D. L., Clay, J. Z., \& Upshaw, J. D. (2021). The Association between Imagination and Anxiety in the Times of the COVID-19 Pandemic. Creativity Research Journal, 33(3), 264-274. https://doi.org/10.1080/10400419.2020.1871549

Zhou, H.-X., Chen, X., Shen, Y.-Q., Li, L., Chen, N.-X., Zhu, Z.-C., Castellanos, F. X., \& Yan, C.-G. (2020). Rumination and the default mode network: Meta-analysis of brain imaging studies and implications for depression. Neuroimage, 206, 116287. https://doi.org/10.1016/j.neuroimage.2019.116287

Zillmann, D., \& Bryant, J. (1985). Selective-exposure phenomena. In D. Zillmann \& J. Bryant (Eds.), Selective Exposure to Communication (pp. 1-10). Lawrence Erlbaum Associates. 